\title{
Using MESIMS to Analyze Polymer MALDI Matrix Solubility
}

\author{
Scott D. Hanton \\ Air Products and Chemicals, Inc., Allentown, Pennsylvania, USA
}

\author{
Kevin G. Owens \\ Department of Chemistry, Drexel University, Philadelphia, Pennsylvania, USA
}

The development of reliable sample preparation methods has been critical to the success of matrix-assisted laser desorption/ionization (MALDI) mass spectrometry experiments. Good MALDI sample preparation for polymers involves choosing the solvent system, the matrix, and the ionization agent correctly, and combining them in a manner that will lead to a sample that will produce the desired ions. The vast diversity of chemistry available in industrial polymers has challenged our ability to design reliable sample preparation methods. In the experiments reported here, we show that matrix-enhanced secondary ion mass spectrometry (MESIMS) is an effective analytical technique to explore sample segregation in solid phase MALDI samples. Qualitative comparison of MESIMS and MALDI results for polymer samples prepared with multiple matrices aids our investigation of the solid-phase solubility of a variety of low molecular weight polymer materials. Including the solid-phase solubility with the liquid-phase solubility of the polymer samples and the matrices enables the construction of a relative solubility chart, which shows the best solubility matches between the polymer and matrix materials for MALDI experiments. (J Am Soc Mass Spectrom 2005, 16, 1172-1180) () 2005 American Society for Mass Spectrometry

$\mathrm{M}$ atrix-enhanced secondary ion mass spectrometry (MESIMS) is a relatively new analytical technique [1-5] developed as a cross between static secondary ion mass spectrometry (SSIMS) [6-8] and matrix-assisted laser desorption ionization (MALDI) [9-13] mass spectrometry. MESIMS takes advantage of the surface sensitivity of SSIMS and incorporates the advantages available from appropriate sample preparation of MALDI. MESIMS has been shown to be effective for some biomolecules [1,2] and for a few low molecular weight polymers [2-5]. In these experiments, we test the effectiveness of MESIMS to probe solid-phase solubility issues for MALDI sample preparation.

MALDI techniques have been developed to determine the chemical structure of a variety of industrial polymers [14-27]. Important information that can be determined includes the monomer mass, end group mass, and molecular weight distribution (including the number average molecular weight, $\mathrm{M}_{\mathrm{N}}$, the weight average molecular weight, $\mathrm{M}_{\mathrm{W}}$, and the polydispersity, PD). Since the introduction of MALDI, the development of reliable sample preparation methods has been critical to the success of MALDI experiments. Good MALDI

Published online May 31, 2005

Address reprint requests to Dr. S. D. Hanton, Air Products and Chemicals, Inc., 7201 Hamilton Blvd., Allentown, PA 18195, USA. E-mail: HantonSD@airproducts.com sample preparation for polymers involves choosing the solvent system, the matrix, and the ionization agent correctly, and combining them in a manner that will lead to a sample that will produce the desired ions. The vast diversity of chemistry in industrial polymers has challenged our ability to design reliable sample preparation methods. It has become clear that matching the solubility of the analyte polymer with the solvent and the matrix is important in wet MALDI sample preparation to generate samples with a high probability of generating a useful MALDI mass spectrum [28].

Wet MALDI sample preparation involves two different regimes of solubility issues. In the liquid phase, we must prepare good analyte and matrix solutions and be able to combine these solutions to effectively mix the analyte and the matrix [28, 29]. When the analyte/ matrix solution is applied to the target, solubility issues are important in the relative rate and order of precipitation of the analyte and matrix from the combined solution. Some of these liquid-phase solubility issues were previously investigated [29]. As the solvent evaporates, solid-phase solubility issues become important. In the solid phase, we would like to know if the analyte is located somewhere within the matrix crystal [30,31], if any species are excluded from the crystal, the relative locations of the analyte and any required cationization agent, and any orientation of the matrix crystals. The liquid-phase solubility issues are often vital to the successful development of most reliable, wet MALDI 
sample preparation methods and we have a variety of methods to investigate them. In the study reported here, we explore some of the solid-phase solubility issues with MESIMS.

\section{Experimental}

\section{Chemicals}

Uninhibited tetrahydrofuran (THF), methanol (MeOH), and acetone were obtained from Fisher (Pittsburgh, PA). Water was obtained from our house deionized water system.

Tables 1 and 2 list the set of low molecular weight polymers and the set of MALDI matrices we investigated.

The PEG, PMMA, PS, and PBD samples were obtained from Aldrich (Milwaukee, WI). The PPO sample was obtained from ARCO (Newtown Square, PA). The PEF and PVAc samples were synthesized in-house. The PTMEG sample was obtained from BASF (Florham Park, NJ). The PDMS sample was obtained from American Polymer Standards Corporation (Mentor, OH). All of the matrices were obtained from Aldrich. Silver trifluoroacetate (AgTFA) was obtained from Aldrich. All chemicals were used as received.

\section{Sample Preparation}

For these experiments, we used typical MALDI sample preparation methods, with the objective of investigating the effects of solid-phase solubility on MALDI experiments. No attempt was made to optimize the sample preparation methods for MESIMS. Our typical sample preparation for low molecular weight polymers is to prepare a $5 \mathrm{mg} / \mathrm{mL}$ analyte solution and mix it 2:7 by volume with a $0.25 \mathrm{M}$ matrix solution in the same solvent. Whenever possible, the same solvent is used for both the analyte and the matrix. For these experiments, we used solvents that we matched for the analyte and the matrix. They included methanol, acetone, and THF. All solutions were prepared in soft glass vials. Adventitious sodium from the glass and sodium contamination from the matrix materials provided the alkali cationization agent for the oxygen functional polymer samples. For the polymer samples requiring silver cationization (polystyrene and polybutadiene), a 5 $\mathrm{mg} / \mathrm{mL}$ solution of silver trifluoroacetate in THF was

Table 1. Polymers investigated

\begin{tabular}{lc}
\hline Polymers & MW (D) \\
\hline \hline Polyethylene glycol (PEG) & 1000 \\
Polypropylene glycol (PPO) & 2025 \\
Polyethynl formamide (PEF) & 1500 \\
Polyvinyl acetate (PVAc) & 1500 \\
Polytetramethylene glycol (PTMEG) & 1800 \\
Polymethylmethacrylate (PMMA) & 2900 \\
Polystyrene (PS) & 2450 \\
Polybutadiene (PBD) & 1300 \\
Polydimethylsiloxane (PDMS) & 1500 \\
\hline
\end{tabular}

Table 2. Matrices investigated

Thiourea (TU)

2,5-Dihydroxybenzoic acid (DHB)

$\alpha$-cyano-4-hydroxycinnamic acid (CHCA)

Ferulic acid (FA)

Indole acrylic acid (IAA)

Dithranol (Dith)

Trans,trans-retinoic acid (RA)

Diphenyl butadiene (DPBD)

added to the analyte/matrix solution in the same volume as the analyte. For these experiments, approximately $2 \mu \mathrm{L}$ of sample was deposited on $\mathrm{Al}$ targets and allowed to air dry. Because we wanted to investigate typical MALDI sample preparations, no electrospray deposited samples were analyzed in this study $[3,32]$.

\section{Mass Spectrometry}

Most of these experiments were conducted on a Physical Electronics (Eden Prairie, MN) TRIFT II time-offlight mass spectrometer (TOFMS) equipped with both a ${ }^{69} \mathrm{Ga}$ liquid metal ion gun (600 pA) for TOF-SIMS experiments and a $\mathrm{N}_{2}$ laser (Laser Photonics, Lake Mary, FL, $337 \mathrm{~nm}, 600 \mathrm{ps}$ pulsewidth) for MALDI experiments [3, 33, 34, 35]. The instrument measures mass via time-of-flight, but incorporates both a short linear flight tube and three electrostatic sectors for a curved flight path. The total flight path is approximately $2 \mathrm{~m}$. Ions are detected by a dual microchannel plate $(\mathrm{MCP})$ detector. Only positive ion mass spectra are reported in this paper.

In MALDI mode, we greatly attenuated the laser. Experiments were done with laser fluence slightly above threshold for MALDI. The optical system used on the TRIFT instrument produces a very small laser spot, a circle about $4 \mu \mathrm{m}$ in diameter. Spectra were obtained from 125 laser pulses. Desorbed ions were extracted with an electric field imparting $3.2 \mathrm{kV}$ of kinetic energy. Ions experienced $7 \mathrm{kV}$ of post-acceleration just prior to detection. Signal from the detector was digitized and averaged in a digital oscilloscope (LeCroy 9350, 2 ns/channel, $200 \mu$ s record length, $200 \mathrm{mV}$ sensitivity, and $-790 \mathrm{mV}$ offset).

In TOF-SIMS mode we used a $15 \mathrm{kV}$ (14 ns pulsewidth) bunched primary ion beam. Typical mass resolution was 7000 at $100 \mathrm{D}$. Typical repetition rates were $5-15 \mathrm{kHz}$. During the analysis the ion gun was rastered over a $200 \mu \mathrm{m} \times 200 \mu \mathrm{m}$ area. The secondary ions were extracted using an electric field imparting $3.2 \mathrm{kV}$ of kinetic energy. Ions experienced $7 \mathrm{kV}$ of post-acceleration just prior to detection. Signals from the detector were processed by a multistop time-to-digital converter with 138 ps time resolution. Typically, data was acquired for $10 \mathrm{~min}$.

In SSIMS experiments of insulating samples, surface charging is often a problem. The TRIFT instrument is equipped with a pulsed charge compensator to mitigate 
Table 3. MALDI matrix liquid-phase qualitative solubility

\begin{tabular}{|c|c|c|c|c|c|c|}
\hline Matrix/solvent & Water & $\mathrm{MeOH}$ & Acetone & THF & $\mathrm{CHCl}_{3}$ & Toluene \\
\hline$\overline{T U}$ & $\mathrm{~S}$ & $\mathrm{~s}$ & $\mathrm{~s}$ & $\mathrm{~N}$ & $\mathrm{~N}$ & $\mathrm{~N}$ \\
\hline SA & $P$ & $S$ & S & $S$ & $\mathrm{~N}$ & $\mathrm{~N}$ \\
\hline DHB & $P$ & S & S & $S$ & $P$ & $P$ \\
\hline $\mathrm{CHCA}$ & $\mathrm{N}$ & $P$ & $P$ & $S$ & $\mathrm{~N}$ & $\mathrm{~N}$ \\
\hline FA & $\mathrm{N}$ & S & $\mathrm{S}$ & $\mathrm{S}$ & $\mathrm{N}$ & $\mathrm{N}$ \\
\hline IAA & $\mathrm{N}$ & $P$ & $\mathrm{~S}$ & $S$ & $\mathrm{~N}$ & $\mathrm{~N}$ \\
\hline Dith & $\mathrm{N}$ & $P$ & $\mathrm{~N}$ & $P$ & $P$ & $P$ \\
\hline RA & $\mathrm{N}$ & $\mathrm{N}$ & $\mathrm{N}$ & $S$ & S & $\mathrm{N}$ \\
\hline DPBD & $\mathrm{N}$ & $P$ & $S$ & $S$ & $S$ & $S$ \\
\hline
\end{tabular}

this problem. In these experiments, we did not observe any problems with surface charging. Experiments conducted with and without the charge compensator produced the same results. While polymer films can be good insulators leading to charging problems, the air dried MESIMS samples are thin films with many defects where the underlying metal substrate shows through. This access to the metal substrate apparently solves any surface charging problem.

The final MALDI experiment shown testing the sample preparation guidelines was done on a Bruker Biflex III TOFMS (Billerica, MA) equipped with both a reflectron and delayed extraction. The sample was analyzed using instrument parameters optimized at 3000 D.

\section{Results and Discussion}

To investigate solid-phase solubility effects in MALDI sample preparation by MESIMS we need a relatively diverse set of analytes and matrices. Tables 1 and 2 list the set of low molecular weight polymers and MALDI matrices we investigated. Low molecular weight polymers were required for the MESIMS experiments. Without optimization of the MESIMS experiment, only relatively low mass oligomers were observed in this study.

To develop wet sample preparation methods for MALDI, we provide some simple, qualitative liquidphase solubility results for the polymers and matrices used in this study. The polymers were evaluated as 5 $\mathrm{mg} / \mathrm{mL}$ solutions and the matrices were evaluated as $0.25 \mathrm{M}$ solutions. Tables 3 and 4 show the results. The letter $S$ in Tables 3 and 4 indicates that the material was soluble to at least the desired level. The polymer or matrix made a clear solution in that solvent. The letter $\mathrm{P}$ indicates that the material was partially soluble, but not completely soluble to the desired level. The polymer or matrix made a mostly clear solution with a small amount of haziness in that solvent. The letter $\mathrm{N}$ indicates that the material was not usefully soluble. The matrix or polymer was clearly not dissolved. It produced a two phase mixture with that solvent. Combinations that result in $\mathrm{N}$ do not result in successful MALDI experiments. While these data are completely qualitative, they are sufficient for us to develop new sample preparation methods.

We prepared and ran MALDI and MESIMS experiments on a variety of combinations of analytes and matrices. The MALDI experiments on these low molecular weight samples are relatively uncomplicated and have a high success rate (if an appropriate sample preparation method is used). The new information comes from the comparisons between the MESIMS results and the MALDI results. A successful MALDI experiment provides a needed check on the quality of the sample preparation.

Figure 1 shows four MESIMS mass spectra of PMMA 2900 prepared in THF with four different matrices: DHB, CHCA, FA, and IAA. In Figure $1 \mathrm{a}$ and b, we see oligomer distributions of the PMMA sample. In Figure 1c and $d$, we do not see any ions that indicate a distribution of oligomers. The only difference in these experiments is the matrix used in the sample preparation. The successful MALDI experiments shown in Figure 2 demonstrate that all four samples were prepared correctly for MALDI. We see nearly identical MALDI mass spectra for all four matrices. These matri-

Table 4. Low molecular weight polymer liquid-phase qualitative solubility

\begin{tabular}{|c|c|c|c|c|c|c|}
\hline Polymer/solvent & Water & $\mathrm{MeOH}$ & Acetone & THF & $\mathrm{CHCl}_{3}$ & Toluene \\
\hline PEG 1500 & $\mathrm{~S}$ & $\mathrm{~S}$ & $\mathrm{~S}$ & $\mathrm{~S}$ & $\mathrm{~S}$ & $\mathrm{~S}$ \\
\hline PPG 2025 & $\mathrm{~N}$ & $\mathrm{~S}$ & $\mathrm{~S}$ & $\mathrm{~S}$ & $\mathrm{~S}$ & $\mathrm{~S}$ \\
\hline PEF 1500 & $\mathrm{~S}$ & $\mathrm{P}$ & $\mathrm{N}$ & $P$ & $\mathrm{~N}$ & $\mathrm{~N}$ \\
\hline PVAc 1500 & $\mathrm{P}$ & $\mathrm{s}$ & $\mathrm{S}$ & $\mathrm{S}$ & $\mathrm{S}$ & $\mathrm{S}$ \\
\hline PTMEG 1800 & $\mathrm{~N}$ & $\mathrm{~S}$ & S & $\mathrm{S}$ & $\mathrm{S}$ & $\mathrm{S}$ \\
\hline PMMA 2900 & $\mathrm{~N}$ & $\mathrm{~S}$ & $\mathrm{~S}$ & $\mathrm{~S}$ & $\mathrm{~S}$ & $\mathrm{~S}$ \\
\hline PS 2450 & $\mathrm{~N}$ & $\mathrm{~N}$ & $\mathrm{~S}$ & $\mathrm{~S}$ & $\mathrm{~S}$ & $\mathrm{~S}$ \\
\hline PBD 1300 & $\mathrm{~N}$ & $\mathrm{~N}$ & $P$ & $\mathrm{~S}$ & $\mathrm{~S}$ & $\mathrm{~S}$ \\
\hline PDMS 1500 & $\mathrm{~N}$ & $\mathrm{~S}$ & S & $\mathrm{S}$ & $\mathrm{S}$ & $\mathrm{S}$ \\
\hline
\end{tabular}




\section{DHB}

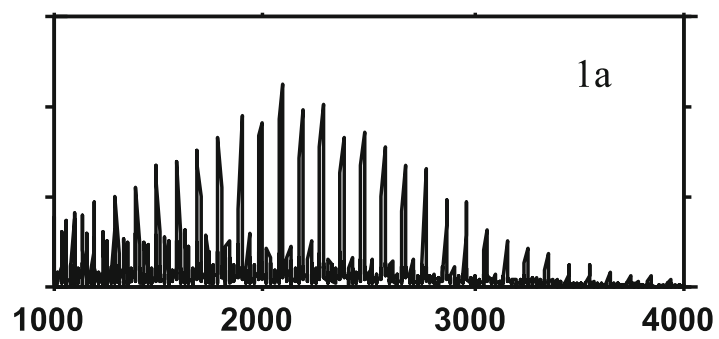

FA

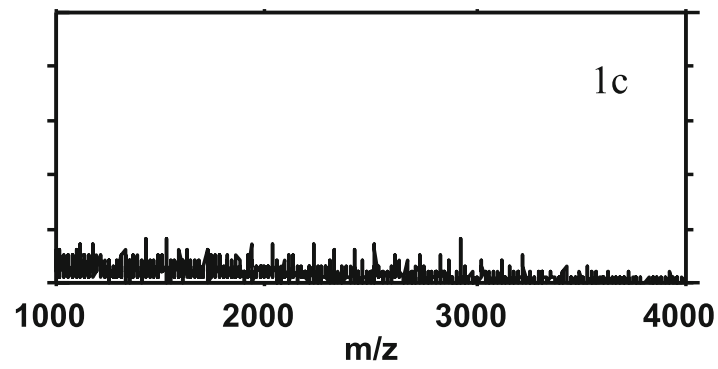

CHCA

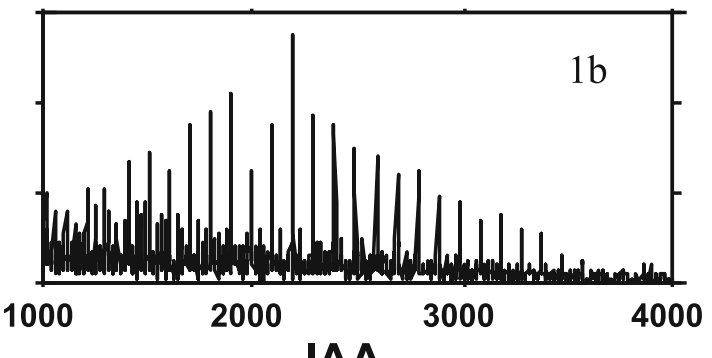

IAA

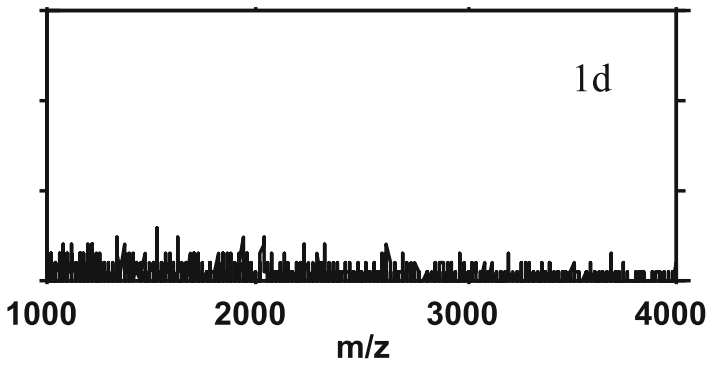

Figure 1. MESIMS mass spectra of PMMA 2900 prepared with different matrices: (a) DHB, (b) CHCA, (c) FA, and (d) IAA. Useful mass spectra were obtained only for the DHB and CHCA matrices.

ces are sufficiently similar that we expected them all to work well for PMMA 2900 by MALDI.

We observe similar results for other polymers besides PMMA 2900. Figure 3 shows four MESIMS mass spectra of PS 2450 prepared in THF with four different matrices: CHCA, RA, DPBD, and Dith. We see ion signal for the oligomers from the samples prepared with CHCA and DPBD, but observe no ion signal indicating oligomer distributions when the samples are prepared with RA and Dith. Figure 4 shows four MESIMS mass spectra for PBD 1300 prepared with DHB, CHCA, Dith, and DPBD. We observe ion signal for the oligomers from the samples prepared with CHCA and Dith, but observe no ion signal indicating an oligomer distribution from the samples prepared with DHB and DPBD. As with PMMA 2900, the MESIMS results are largely dependent on the choice of matrix.

In the MESIMS experiments, we see results ranging from high signal-to-noise ions, clearly indicating an oligomer distribution, to no polymer ions detected. Qualitatively, the results are grouped into two primary populations, those that produced an easily recognized oligomer distribution and those that produced essentially no oligomer ions at all. The high surface sensitiv-
DHB
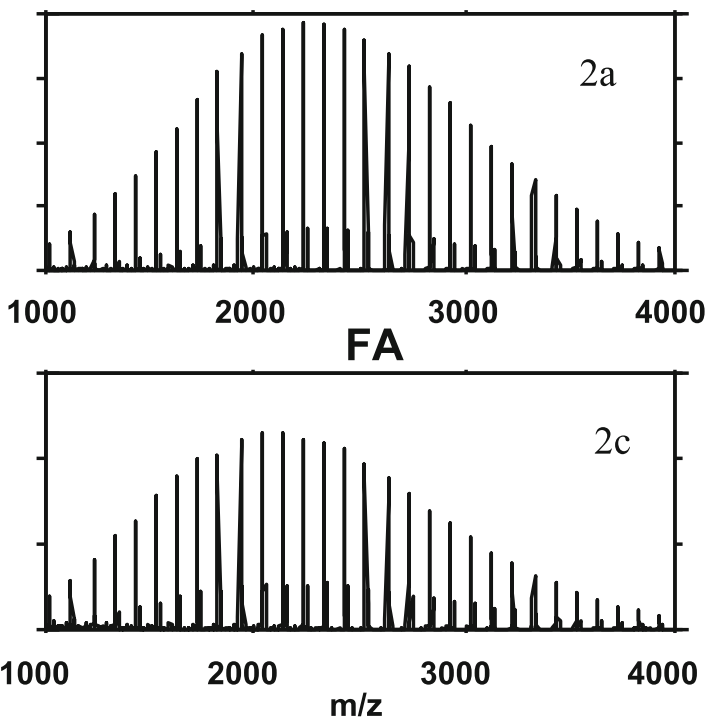

CHCA
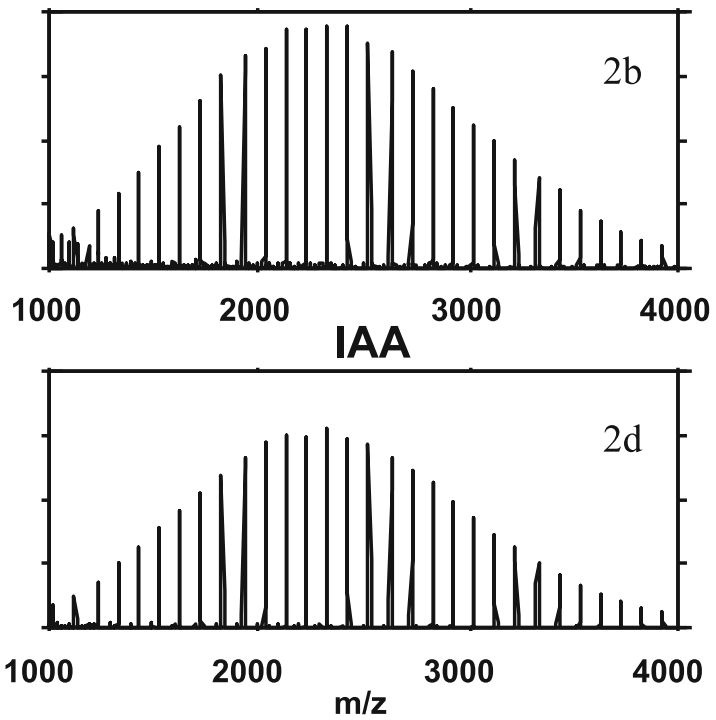

Figure 2. MALDI mass spectra of PMMA 2900 prepared with different matrices: (a) DHB, (b) CHCA,

(c) FA, and (d) IAA. Useful mass spectra were obtained for all of the matrices. 


\section{CHCA}
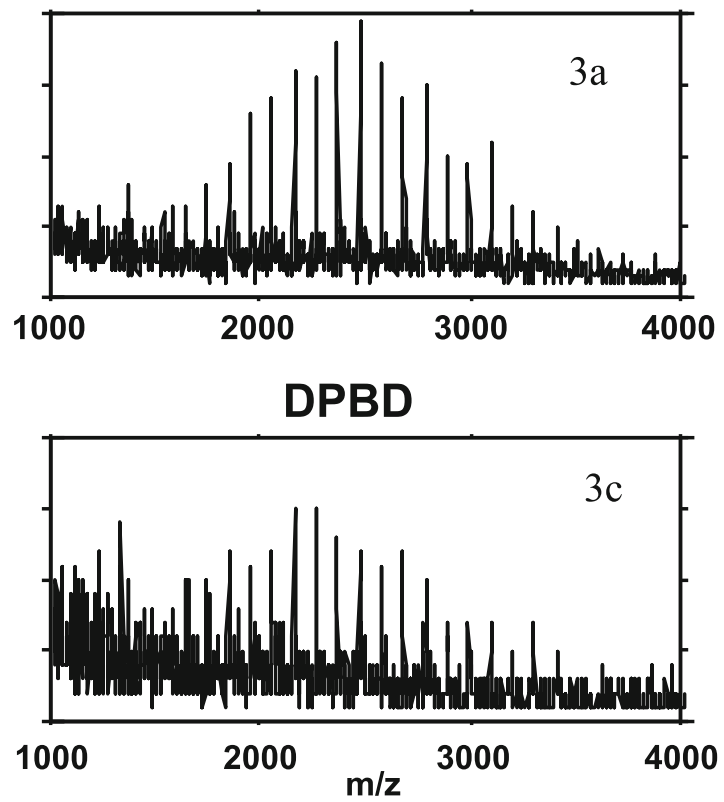

RA

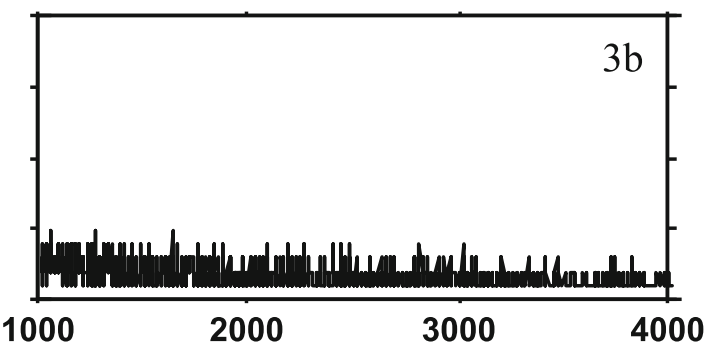

Dithranol

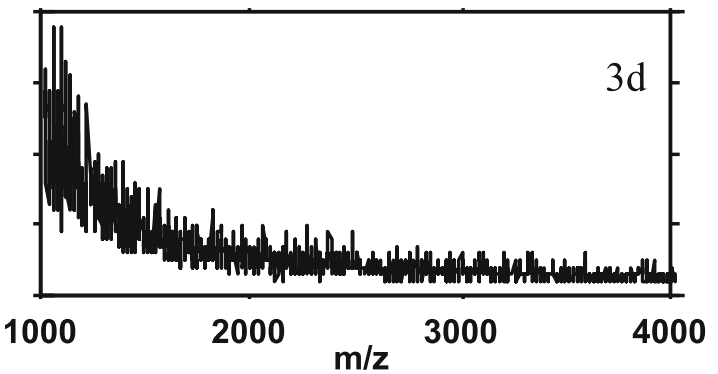

Figure 3. MESIMS mass spectra of PS 2450 prepared with different matrices: (a) CHCA, (b) RA, (c)

DPBD, and (d) Dith. Useful mass spectra were obtained only for the CHCA and DPBD matrices.

ity of SSIMS limits the observed ions to originating from the top few monolayers of the surface. If oligomer ions are observed by MESIMS, a significant number of intact polymer oligomers must be present and free on the surface of the matrix crystals. If no oligomer ions are observed, either the analyte must be significantly fragmented by SSIMS, or there is not a significant number of oligomers present and free on the surface of the matrix crystals. Since all of the polymer samples produce useful oligomer signal from at least one of the matrices, and the SSIMS bombardment is constant for each of the experiments, fragmentation is not likely to be the primary cause of the absence of oligomer signal. Therefore, we conclude that the absence of oligomer signal indicates an absence of free oligomers on the surface of the matrix crystals. Since we know the polymer was added to the preparation, and the successful MALDI experiments demonstrate proper MALDI sample preparation,
DHB

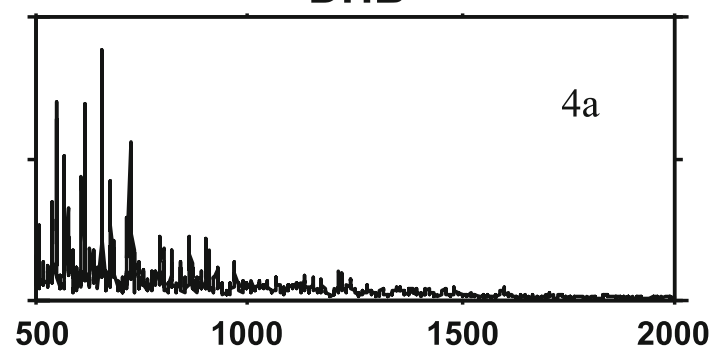

Dithranol

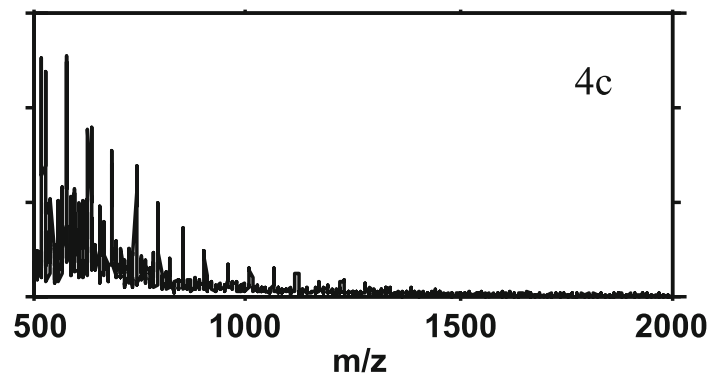

CHCA
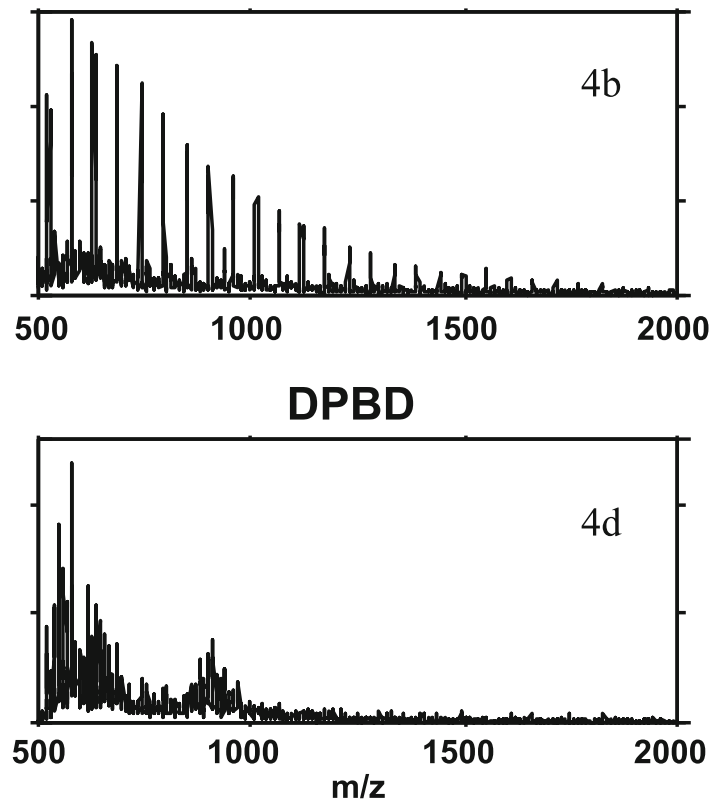

Figure 4. MESIMS mass spectra of PBD 2450 prepared with different matrices: (a) DHB, (b) CHCA, (c) Dith, and (d) DPBD. Useful mass spectra were obtained only for the Dith and CHCA matrices. 
Table 5. MESIMS results

\begin{tabular}{|c|c|c|c|c|c|c|c|c|c|}
\hline Polymer & $\begin{array}{l}\text { PEG } \\
1000\end{array}$ & $\begin{array}{l}\text { PPO } \\
2025\end{array}$ & $\begin{array}{l}\text { PEF } \\
1500\end{array}$ & $\begin{array}{l}\text { PVAc } \\
1500\end{array}$ & $\begin{array}{l}\text { PTMEG } \\
1800\end{array}$ & $\begin{array}{l}\text { PMMA } \\
2900\end{array}$ & $\begin{array}{l}\text { PS } \\
2450\end{array}$ & $\begin{array}{l}\text { PBD } \\
1300\end{array}$ & $\begin{array}{l}\text { PDMS } \\
1500\end{array}$ \\
\hline DPBD & & & & yes & no & no & yes & no & yes \\
\hline RA & & no* & & & & no* & no & no & yes \\
\hline Dith & & & yes & no & no & no & no & yes & no \\
\hline IAA & yes & yes & no & no & no & no & yes & yes & yes \\
\hline FA & yes & yes & yes & yes & no & no & no & yes & yes \\
\hline $\mathrm{CHCA}$ & yes & yes & yes & yes & yes & yes & yes & yes & yes \\
\hline DHB & yes & yes & yes & yes & yes & yes & yes & no & yes \\
\hline TU & yes & & no & no & yes & & & & \\
\hline
\end{tabular}

* See text for explanation of asterisk.

if the analyte is not present on the surface, then it must be below the surface, located somewhere within the matrix. Thus, the absence of observed oligomers by MESIMS is interpreted as evidence for improved compatibility of the polymers within the matrix.

Table 5 lists the results of a variety of different sample preparations. We have categorized the results of the MESIMS experiments qualitatively as showing oligomer ion signal (yes), or not showing oligomer ion signal (no).

In Table 5 we see a central region with a significant number of "no" results. The "no" results indicate an increased incorporation of the analyte by the matrix crystals. This increased incorporation is interpreted as showing an improved solid-phase solubility match between the analytes and the matrices.

Two of the "no" results are marked with an asterisk. In both of these cases, we are observing an absence of oligomer ion signal, but this absence may not be due to a solubility match between the polymer and the matrix. In both of these cases the matrix is RA. Further investigation of the RA samples showed that significant segregation of the sodium cationization agent may be solely responsible for the absence of oligomer ion signal. In the sample of PMMA 2900 prepared with RA, we clearly see a large (saturated) $\mathrm{Na}^{+}$peak (data not shown). In the high mass region of the MALDI mass spectrum, we observe sodium cationized oligomer ions. In the MESIMS mass spectrum, however, we see only a very tiny $\mathrm{Na}^{+}$peak and no oligomer ions of sodium cationized PMMA. These data indicate that the sodium is segregated away from the surface of the RA crystals. The structure of RA is similar to a fatty acid, with hydrophobic alkyl and hydrophilic carboxylic acid ends to the molecule. Some fatty acids will orient with the carboxylic acid groups together on the inside of a layer, and the hydrophobic ends extending towards the surface [35]. It appears that RA shows the same type of orientation in these crystals. There is no sodium on the surface, so we observe no polymer oligomer ions by MESIMS. In the MALDI experiment, there is sufficient depth of analysis to reach the sodium and produce cationized oligomers.

While these MESIMS experiments can provide important insight to the relative solid-phase solubility of
MALDI matrices and analytes, the experiments do have important limitations. So far, we have been limited to low molecular weight polymers for MESIMS. As the molecular weight increases, so does the rate of fragmentation during MESIMS [3]. Our experiments indicate that different chemistry has different upper mass limits for MESIMS. PEG has a low upper mass limit of about 1500 D, and PS has the highest mass sample that we have successfully analyzed by MESIMS of 5500 D. For these experiments, we have made no attempt to optimize the MESIMS experiment since we wanted to probe details of optimized MALDI sample preparations. Future work will include studies of optimized MESIMS sample preparations to try to extend the mass range.

The interpretation of our MESIMS data (as shown in Table 5) also suffers from the complexity of the chemistry we probe. In addition to the issues of solubility that we wish to further understand, we see issues related to the difference between solubility and surfactancy, and issues about the generality of some matrices. We obtain our best relative solubility data from the central region of Table 5. The edge columns of Table 5 show issues of surfactancy. Both PEG 1000 and PDMS 1500 are highly surface-active species. They may migrate to the surfaces of the matrix crystals because of their surface activity rather than be excluded from the crystals because of their relative solid-phase solubility. The end result is the same but the driving force may be different. Not only is the PDMS 1500 solid-phase solubility difficult to interpret with the MESIMS, it is also difficult to interpret with the liquid-phase solubility.

Two of the matrices in Table 5, DHB and CHCA, show almost no differentiation with the various polymers. It appears that for these low molecular weight polymer analytes, they behave similarly, independent of the liquid solubility of the analytes. Therefore, we obtain very little information about the solid-phase solubility of the polymers with these matrices. Because of their importance to the MALDI community, we will include them in the integrated solubility chart, but base their relative positions on the liquid-phase solubility data.

Using the data presented in Tables 3 through 5 we can group both the polymers and the matrices by relative solubility. We present these results in Figure 5 


\section{Matrix and Polymer Relative Solubilities}

\begin{tabular}{|c|c|}
\hline Matrices & Polymers \\
\hline \multicolumn{2}{|c|}{ Hydrophilic } \\
\hline TU & PEG \\
\hline DHB & PPO \\
\hline & PEF \\
\hline & PVAc \\
\hline IAA & \\
\hline CHCA & PTMEG \\
\hline FA & PMMA \\
\hline Dith & \\
\hline DPDB & PS \\
\hline RA & PBD \\
\hline & \\
\hline
\end{tabular}

Figure 5. Relative matrix and polymer solubility scale developed from the MESIMS and liquid-phase solubility data presented here. The more hydrophilic matrices and polymers are at the top of the figure and the more hydrophobic matrices and polymers are at the bottom of the figure.

showing both grouped by relative hydrophilicity. The most hydrophilic materials are at the top of the list and the most hydrophobic materials are at the bottom of the list. Thiourea is the most hydrophilic matrix by both liquid solubility and by the MESIMS data. The middle group contains IAA and FA. The more hydrophobic matrices include Dith, DPDB and RA. The liquid solubility data indicates that DHB should fall between TU and the middle group, and that CHCA should be similar to the others in the middle group. For the polymers, we can group PEG, PPO, PEF, and PVAc in the most hydrophilic group; PTMEG and PMMA in the middle group; and PS and PBD in the most hydrophobic group. Because of problems in interpreting the PDMS data, we have chosen to exclude it from Figure 5.

While it is relatively easy for us to group the matrices and analytes, separately, the key is to coordinate the two lists. We rely on the MESIMS data to give us the information to accomplish that. The solubility matches between TU and PEF and PVAc in Table 5 allow us to coordinate the two most hydrophilic groups. The matches in the center of Table 5 between IAA and FA with PTMEG and PMMA enable us to coordinate the middle groups. The slight differences between the match with FA and PS and the match between IAA and PVAc enable us to order the matrices in the middle group. The matches in the upper right hand corner of Table 5 enable us to coordinate the hydrophobic groups and to order these matrices.

While Figure 5 is qualitative in nature, the information content may be useful to the polymer MALDI community to aid in the development of new sample preparation methods. We expect to see the best solubility matches by pairing analytes and matrices from the same general regions of the figure. When MALDI data is needed for a new polymer material, we recommend these steps to shorten the time required to develop the new sample preparation method:
1. Determine the solvent(s) good enough to obtain a transparent $5 \mathrm{mg} / \mathrm{ml}$ analyte solution.

2. Compare the liquid-phase solubility of the new polymer to the polymers listed in Table 4 .

3. Find the polymer(s) in Table 4 that compare best to the new polymer.

4. Use Figure 5 to determine the group of matrices that best match with the comparable polymer(s).

5. Prepare the new polymer with those matrices in the solvent determined in the first step.

To test the hypotheses outlined in the five steps above, we collaborated with Professor Li Jia of Lehigh University to analyze novel materials resulting from the copolymerization of $\mathrm{N}$-allylaziridines and carbon monoxide [36]. For example, the copolymerization of N-ethylaziridine with $\mathrm{CO}$ resulted in a material that was soluble in water and water/methanol, and partially soluble in methanol. Compared with the results in Table 4, we find the best match for PEF 1500 . We find PEF 1500 in the most hydrophilic group in Figure 5, which suggests that either TU or DHB would be the best first choice for a matrix. Figure 6 shows the mass spectrum of the material prepared using methanol as the solvent and DHB as the matrix. The mass spectrum confirms the expected repeat units and end groups in the polymer. This is an example of the analysis of a new polymeric material that, to our knowledge, had never been analyzed previously by MALDI. In a matter of a few minutes, a sample preparation method was determined from the data presented here and successfully applied. In the absence of these data, the development of new sample preparation methods can be a long and tedious process of trial and error.

In the process of obtaining the relative solubility information by MESIMS, we have observed that MESIMS can be an effective analytical tool for examining a wide variety of low molecular weight polymer samples. For each of the polymers listed in Table 1, we had conditions that generated oligomer mass spectra by MESIMS. MESIMS has the added advantage of generating some useful fragmentation data that may be useful to help identify chemical structures. While not mass selected fragmentation, like post-source decay (PSD), these data may be useful in a complementary way. In our experience, the MESIMS fragments have significantly higher mass resolution and mass accuracy than MALDI-PSD. While some polymers have been previously analyzed by MESIMS [2, 3], these are the first examples that MESIMS can be successfully applied to a broad variety of oligomer samples.

\section{Conclusions}

We have generated MESIMS data for a variety of low molecular weight polymer samples prepared in a variety of typical MALDI matrices. The MESIMS experimental results group into two categories, spectra with visible oligomer distributions and spectra 


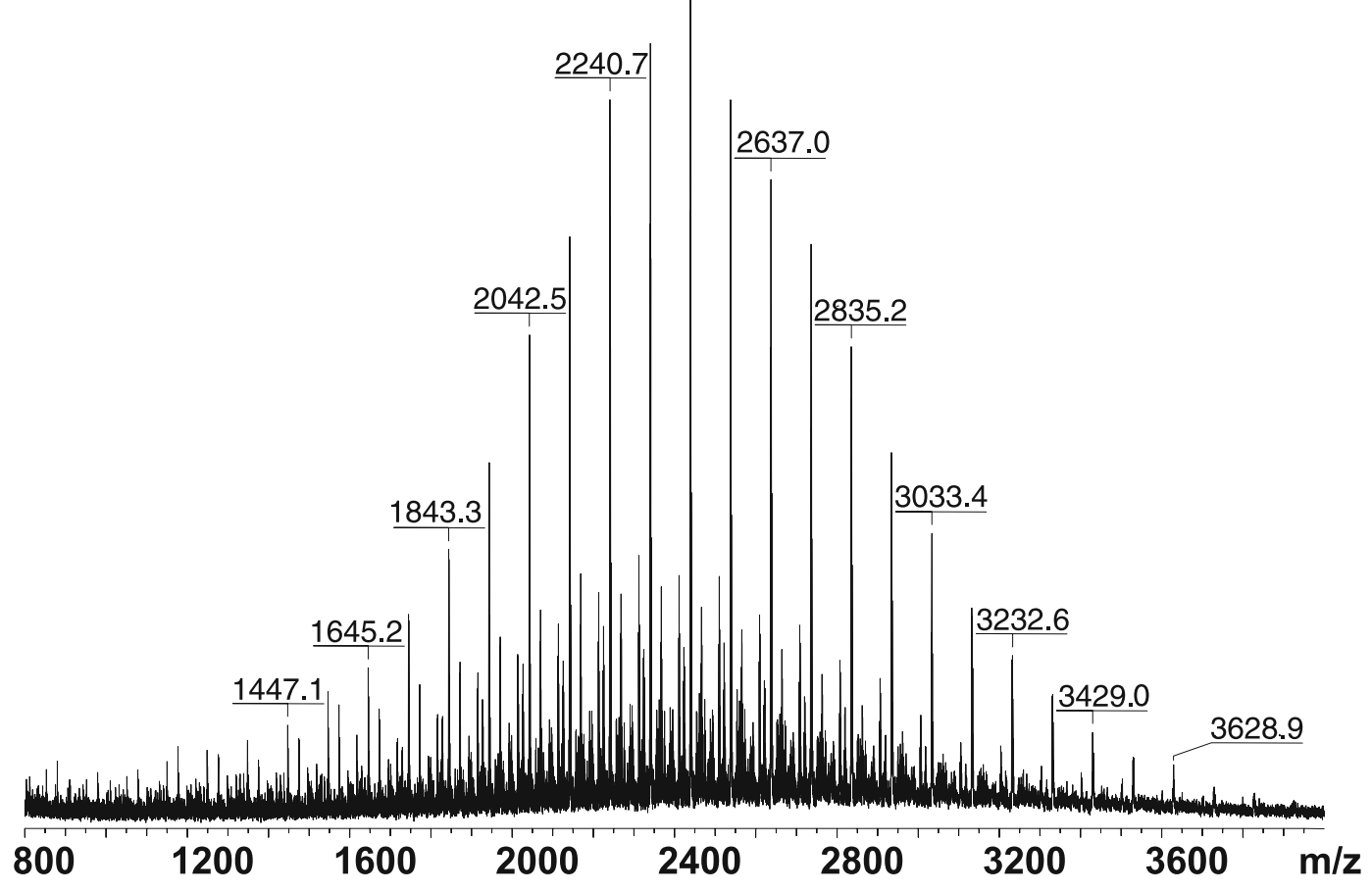

Figure 6. MALDI mass spectrum of a novel polymeric material produced from the copolymerization of N-ethylaziridine with CO. The sample was prepared using methanol and DHB.

without visible oligomer distributions. From the observed presence or absence of polymer signal in the MESIMS experiments, we can group both the matrices and the polymers in relative solubility order. This improved solubility information for both the matrices and the polymers will aid in new sample preparation method development.

In addition to the new relative solid-phase solubility data for these polymers and matrices, we also obtained MESIMS mass spectra for each of the low molecular weight polymers studied. This work demonstrates that MESIMS can be an interesting analytical technique complementary to MALDI for oligomer samples.

\section{Acknowledgments}

The authors thank Air Products and Chemicals, Inc. for its support of this research, Mr. Glenn Mitchell and Ms. Tong Sun for some of the liquid-phase solubility data, Dr. Robert Pinschmidt and Mr. Khalil Yacoub for the PEF and PVAc samples, Professor Li Jia for collaborating in the analyses of the amine/CO copolymers, Dr. David Parees and Dr. Paula Clark for helpful discussions about the data, and Dr. Robert Coraor for critical review of the manuscript.

\section{References}

1. Wu, K. J.; Odom, R. W. Matrix-Enhanced Secondary Ion Mass Spectrometry: A Method for Molecular Analysis of Solid Surfaces. Anal. Chem. 1996, 68, 873.

2. Nicola, A. J.; Muddiman, D. C.; Hercules, D. M. Enhancement of Ion Intensity in Time-Of-Flight Secondary-Ionization Mass Spectrometry. J. Am. Soc. Mass Spectrom. 1996, 7, 467.
3. Hanton, S. D.; Clark, P. A. C.; Owens, K. G. Investigations of Matrix-Assisted Laser Desorption/Ionization Sample Preparation by Time-of-Flight Secondary Ion Mass Spectrometry. J. Am. Soc. Mass Spectrom. 1999, 10, 104.

4. Hanton, S. D.; Clark, P. A. C.; Owens, K. G. Proceedings of the 45th ASMS Conference on Mass Spectrometry and Allied Topics; Palm Springs, CA, 1997.

5. Hanton, S. D.; Owens, K. G. The Investigation of Polymer and Matrix Solubility by MALD/I and MESIMS. Proceedings of the 46th ASMS Conference on Mass Spectrometry and Allied Topics; Orlando, FL, 1998.

6. Benninghoven, A. Chemical Analysis Of Inorganic and Organic Surfaces and Thin Films Using Time-Of-Flight Secondary Ion Mass Spectrometry (TOF-SIMS), Angew. Chem. Int. Ed. Engl. 1994, 33, 1023.

7. Benninghoven, A.; Rudenaur, F. G.; Werner, H. W. Secondary Ion Mass Spectrometry: Basic Concepts, Instrumental Aspects, Applications, and Trends; John Wiley and Sons: New York, 1987.

8. Vickerman, J. C.; Brown, A.; Reed, N. M. Secondary Ion Mass Spectrometry: Principles and Applications; Clarendon Press: Oxford, 1989.

9. Tanaka, K.; Waki, H.; Ido, Y.; Akita, S.; Yoshido, Y.; Yoshido, T. Protein and Polymer Analyses up to $m / z$ 100,000 by Laser Ionization Time-of-Flight Mass Spectrometry. Rapid Commun. Mass Spectrom. 1988, 2, 151.

10. Karas, M.; Hillenkamp, F. Laser Desorption Ionization of Proteins with Molecular Masses Exceeding 10,000 Daltons. Anal. Chem. 1988, 60, 2299.

11. Bahr, U.; Deppe, A.; Karas, M.; Hillenkamp, F.; Giessman, U. Mass Spectrometry of Synthetic Polymers by UV-Matrix-Assisted Laser Desorption/Ionization. Anal. Chem. 1992, 64, 2866.

12. Hillenkamp, F.; Karas, M.; Beavis, R. C.; Chait, B. T. MatrixAssisted Laser Desorption/Ionization Mass Spectrometry of Biopolymers. Anal. Chem. 1991, 63, A1193. 
13. Beavis, R. C.; Chait, B. T. High-Accuracy Molecular Mass Determination of Proteins Using Matrix-Assisted Laser Desorption Mass Spectrometry. Anal. Chem. 1990, 62, 1836.

14. Bürger, M.; Müller, H.; Seebach, D.; Börnsen, O.; Schär, M.; Widmer, M. Matrix-Assisted Laser Desorption and Ionization as a Mass Spectrometric Tool for the Analysis of Poly[(R)-3Hydroxybutanoates]. Comparison with Gel Permeation Chromatography. Macromolecules 1993, 26, 4783.

15. Blais, J.; Tessier, M.; Bolbach, G.; Remaud, B.; Rozes, L.; Guittard, J.; Brunot, A.; Maréchal, E.; Tabet, J. Matrix-Assisted Laser Desorption Ionization Time-of-Flight Mass Spectrometry of Synthetic Polyesters. Int. J. Mass Spectrom. Ion Processes 1995, 144, 131.

16. Montaudo, G.; Montaudo, M. S.; Puglisi, C.; Samperi, F. Characterization of Polymers by Matrix-Assisted Laser Desorption Ionization-Time of Flight Mass Spectrometry. End Group Determination and Molecular Weight Estimates in Poly(ethylene glycols). Macromolecules 1995, $28,4562$.

17. Danis, P.; Karr, D.; Mayer, F.; Holle, A.; Watson, C. The Analysis of Water-Soluble Polymers by Matrix-Assisted Laser Desorption Time-of-Flight Mass Spectrometry. Org. Mass Spectrom. 1992, 27, 843.

18. Danis, P.; Karr, D. A Facile Sample Preparation for the Analysis of Synthetic Organic Polymers by Matrix-Assisted Laser Desorption/Ionization. Org. Mass Spectrom. 1993, 28, 923.

19. King, R. C.; Owens, K. G. Investigations of the UV MatrixAssisted Laser Desorption Process. Proceedings of the 42nd ASMS Conference on Mass Spectrometry and Allied Topics; Chicago, IL , 1994.

20. Hanton, S. D.; Parees, D. M.; Goldschmidt, R. J.; King, R. C.; Owens, K. G. The Use of Matrix-Assisted Laser Desorption Mass Spectrometry to Investigate Industrial Polymers. Proceedings of the 43rd ASMS Conference on Mass Spectrometry and Allied Topics; Atlanta, GA, 1995.

21. King, R. C.; Owens, K. G.; Hanton, S. D. Separation of the Desorption and Ionization Events in the Matrix-Assisted Laser Desorption/Ionization Experiment. Proceedings of the 43rd ASMS Conference on Mass Spectrometry and Allied Topics; Atlanta, GA, 1995.

22. King, R. C.; Goldschmidt, R. J.; Xiong, Y.; Owens, K. G.; Hanton, S. D. The Role of Solubility in the Preparation of Synthetic Polymer Samples for Analysis by Matrix-Assisted Laser Desorption/Ionization Time-of-Flight Mass Spectrometry. Proceedings of the 43rd ASMS Conference on Mass Spectrometry and Allied Topics; Atlanta, GA, 1995.

23. Hanton, S. D.; Parees, D. M.; Hanley, B. F.; King, R. C.; Owens, K. G. Analysis of Gel Permeation Chromatography Standards by Matrix-Assisted Laser Desorption/Ionization Time-of-Flight Mass Spectrometry. Proceedings of the 43rd ASMS Conference on Mass Spectrometry and Allied Topics; Atlanta, GA, 1995.

24. King, R. C.; Owens, K. G.; Hanton, S. D. Comparison of Ion Detectors for Matrix-Assisted Laser Desorption/Ionization
Time-of-Flight Mass Spectrometry. Proceedings of the 43rd ASMS Conference on Mass Spectrometry and Allied Topics; Atlanta, GA, 1995

25. Lloyd, P.; Suddaby, K.; Varney, J.; Scrivener, E.; Derrick, P.; Haddleton, D. A Comparison Between Matrix-Assisted Laser Desorption/Ionization Time-of-Flight Mass Spectrometry and Size Exclusion Chromatography in the Mass Characterization Of Synthetic Polymers with Narrow Molecular-Mass Distributions: Poly(methyl methacrylate) and Poly(styrene). Euro. Mass Spectrom. 1995, 1, 293.

26. Belu, A.; DeSimone, J.; Linton, R.; Lange, G.; Friedman, R. Evaluation of Matrix-Assisted Laser Desorption Ionization Mass Spectrometry for Polymer Characterization. J. Am. Soc. Mass Spectrom. 1996, 7, 11.

27. Parees, D. M.; Hanton, S. D.; Willcox, D. A.; Clark, P. A. A Comparison of Mass Spectrometric Techniques for Generating Molecular Weight Information on Small Polymers. Polym. Prepr. 1996, 37, 321.

28. King, R. C.; Goldschmidt, R. J.; Xiong, Y.; Owens, K. G.; Hanton, S. D. Proceedings of the 43rd ASMS Conference on Mass Spectrometry and Allied Topics; Atlanta, GA, 1995.

29. Li, L. Instrumental and Analytical Method Development of MALDI-MS for Polymer Analysis. Proceedings of the 46th ASMS Conference on Mass Spectrometry and Allied Topics; Orlando, FL, 1998.

30. King, R. C.; Owens, K. G. Investigations of the UV MatrixAssisted Laser Desorption Process. Proceedings of the 42nd ASMS Conference on Mass Spectrometry and Allied Topics; Chicago, IL, 1994.

31. Mitchell, C. A.; Lovell, S.; Thomas, K.; Savickas, P.; Kahr, B. Charge Transfer Interactions in Dyed Crystals of Aromatic Carboxylic Acids and Their Relevance to MALDI Mass Spectrometry. Angew. Chem. Int. Ed. Engl. 1996, 35, 10219.

32. Hensel, R. R.; King, R. C.; Owens, K. G. Electrospray Sample Preparation for Improved Quantitation in Matrix-Assisted Laser Desorption/Ionization Time-of-Flight Mass Spectrometry. Rapid Commun. Mass Spectrom. 1997, 11, 1785.

33. Schueler, B. Microscope Imaging by Time-of-Flight Secondary Ion Mass-Spectrometry. Microsc. Microanal. Microstruct. 1992, 3,119 .

34. Lindley, P. M.; Reich, F. Organic Secondary Ion Imaging by Time-of-Flight Secondary Ion MS (TOF-SIMS). Proceedings of the 43rd ASMS Conference on Mass Spectrometry and Allied Topics; Atlanta, GA, 1995.

35. Cornelio, P. A. Ion and Electron Spectroscopy of Organic and Polymeric Materials: Aspects of Quantitation and Sampling Depth; Ph.D. Thesis, SUNY, Buffalo, 1990.

36. Jia, L.; Sun, H.; Ding, E.; Allegeier, A. M.; Hanton, S. D. Living Alternating Copolymerization of N-Alkylaziridines and Carbon Monoxide as a Route for Synthesis of Poly- $\beta$-Peptoids. J. Am. Chem. Soc. 2002, 124(25), 72820. 